\title{
ADHD in 140 Characters or Less: an Analysis of Twitter Commentary on Attention Deficit Hyperactivity Disorder in Saudi Arabia
}

\author{
Rabab S. Alharbi \\ Faculty of Education, University of Ottawa, Canada
}

Copyright $\subset 2017$ by authors, all rights reserved. Authors agree that this article remains permanently open access under the terms of the Creative Commons Attribution License 4.0 International License

\begin{abstract}
Internet-based social networks such as Twitter are rapidly gaining popularity among Saudis, and an increasing number of them are using the internet to source information about Attention Deficit Hyperactivity Disorder (ADHD). The Saudi ADHD Society (known in English as the AFTA Society) is the only charity serving people with ADHD in Saudi Arabia. This article examines the representations of ADHD by AFTA Society members on Twitter, because they have come to define how ADHD is talked about in Saudi Arabia. The AFTA Society Twitter account (@adhdarabia) has over 13,500 followers. Tweets posted between December $1^{\text {st }}, 2016$ and January $31^{\text {st }}, 2017$ were collected, with those announcing AFTA events and retweets from other accounts eliminated. This resulted in 141 tweets discussing the nature, causation, and treatment of ADHD. These tweets were analyzed using Foucauldian discourse analysis. Findings reveal that AFTA Society tweets construct ADHD as an experience of suffering, and position children with ADHD as sufferers, often subject to additional problems. An alternative discursive construction of $\mathrm{ADHD}$ is that caring for a child with $\mathrm{ADHD}$ is a 'different' kind of responsibility for parents and teachers, who must be advised by 'experts'. The implications of these discourses are discussed in this paper.
\end{abstract}

Keywords ADHD, Discourses, Twitter, Saudi, Foucauldian Discourse Analysis

\section{Introduction}

Internet-based social networks such as Twitter are rapidly gaining popularity among Saudis (Easton [26], 2013) and an increasing number of Saudis are using the internet to source information about Attention Deficit Hyperactivity Disorder (ADHD) (Alharbi [5], 2017). Twitter (http://twitter.com) is a web-based microblogging platform that allows registered users to post and read short text messages (up to 140 characters) commonly known as tweets (Anthony and Zhang [8], 2017). As of June 30, 2016, 10 years after Twitter launched, the number of users had grown exponentially, reaching 313 million per month globally (see https://about.twitter.com/company accessed May 16, 2017). Of the $58 \%$ of the Saudi population who use the internet (Kemp [44], 2015), 81\% have a Twitter account (Global Digital Statistics [34], 2015). Saudi Arabia, with a population of 32 million, has the fastest growing number of Twitter users in the world (Easton [26], 2013).

Twitter offers researchers access to raw, real-time data (Kealey [43], 2012), and has been called "electronic word of mouth" (Jansen et al. [40], 2009). The fact that real-time discourse is 'searchable' through Twitter, in a way and to an extent that is novel in history (Zappavigna [79], 2011), has made Twitter a fertile medium for academic research. Twitter in Saudi Arabia has been analyzed for commentary on political news (Alothman [7], 2013), a women's right to drive campaign (Almahmoud [6], 2015) and women's identity (Guta and Karolak [36], 2015). Internationally, Twitter studies cover a range of topics, from the statistical properties of Twitter use (Java et al. [50], 2007) and the nature of Twitter users (Krishnamurthy et al. [46], 2008), to its usefulness in raising public awareness of and response to emergency events (De Longueville et al. [24], 2009; Hughes and Palen [39], 2009). Research has also investigated Twitter's role in supporting individuals with mental health problems (Shepherd et al. [66], 2015). McNeill and Briggs [53] (2014) conclude that "Twitter can be a powerful tool for the dissemination and discussion of public health information" (p. 673).

While ADHD in Western countries has long been recognized and increasingly diagnosed in recent years, there is a growing recognition of this disorder as a significant cross-cultural phenomenon (Hinshaw et al. [38], 2011). ADHD is the most commonly diagnosed 
neurobehavioral disorder among children (Mannuzza et al. [52], 2003; Zaki [78], 2013). Global prevalence of ADHD is $5.29 \%$ (Polanczyk et al. [59], 2007), but ADHD prevalence in Saudi is to date uncertain (Zaki [78], 2013). According to Saudi's AFTA Society, prevalence of ADHD in Saudi Arabia is estimated to be $15 \%$, (AFTA Society [3], 2008), which is two and a half times the prevalence of ADHD in North America (Polanczyk et al. [59], 2007).

ADHD is a neurobehavioral condition characterized by three distinctive symptoms: inattention and/or hyperactivity, and impulsivity (Nigg [56], 2006). ADHD symptoms are defined in the Diagnostic and Statistical Manual of Mental Disorders (fifth edition, or DSM-5; American Psychiatric Association [9] [APA] 2013). Saudi Arabia uses the APA's definition and criteria in assessing ADHD.

In 2004, the first (and still the only) organization serving people with ADHD in Saudi Arabia was established. ${ }^{1}$ The Saudi ADHD Society (AFTA Society) ${ }^{2}$, with branches in Riyadh and Jeddah, aims to improve the lives of those diagnosed with ADHD through awareness programs and workshops (AFTA Society [3], 2008). The AFTA Society communicates with the public through various platforms: an official website, Facebook, Twitter, Snapchat and Instagram accounts.

Cha et al. [20] (2010) found that influence is gained in Twitter use through concerted effort, such as tweeting about a single topic. The AFTA Society has over 13,500 followers with more than 8,457 tweets about ADHD as of January $31^{\text {st }}$, 2017. I interviewed six parents, six teachers, and four physicians associated with ADHD in Saudi; most of them said the AFTA Society's Twitter account was their primary source of information from the Society (Alharbi [5], 2017). As the discourses generated by the AFTA Society Twitter account have come to define how ADHD is talked about in Saudi Arabia, I decided to conduct the first study of ADHD discourses as reflected in Twitter use there. In this article, I identify these discourses and assess their implications for families, schools and treatment contexts.

\subsection{Brief History of ADHD}

Many studies of mental disorders subscribe to medical interpretations that situate mental disorders firmly within the realm of medicine. The logic is that the same kinds of processes that cause physical diseases also underlie mental illness; hence they can be treated or cured in the same way - by medical interventions (Southall [67], 2007). This hypothesis has become widely accepted by medical authorities, but disputed by those who believe that ADHD is a construct caused by social factors and/or personality characteristics, and not an objective entity. Those who dispute the medical approach to ADHD advocate replacing

1 It was granted charitable status in 2008 .

2 In English, AFTA conveys the Arabic acronym of ADHD medications with education and cultural modification (e.g., Block [17], 1977).

A review of the history of ADHD reveals the early conclusion that children with ADHD have something wrong with their brains (Southall [67], 2007). In 1775, Weikard, a German physician, published a textbook credited by some as the earliest description of attention disorders (Barkley and Peters [13], 2012). In a section entitled "Sickness of the Spirit", those with attention disorder are characterized as unwary and careless. Weikard attributes their lack of attention to being taught too many things at once, or indeed the opposite - having dull, inactive lives. Either can make the sensory nerve in the brain too "weak" for the constant attention required in daily life (Weikard, 1775 in Barkley and Peters [13], 2012).

In 1902, the English physician George Still described a set of behaviours exhibited by a group of 20 children in his clinical practice. He assumed that these children were deficient in their "moral control", leading to a lack of behavioural control. He argued that lowered moral control is linked to a potentially pathological condition, which may occur independently of any physical disease or intellectual impairment. Much of the modern medical literature on ADHD begins with the descriptions provided by Still (e.g. Barkley, 1990 [11]; Goldstein and Ellison [35], 2002). Barkley[12] (2006) presents Still's work as the point of origin for the discourse on ADHD and calls for the continued reading of Still's papers. Rafalovich [61] (2004) argues, however, that Still's findings do not constitute the medical discovery of ADHD. The children Still studied were thought to have other mental health problems, and there was no hypothesizing about neurological structures at that time, so the conclusions of Still and his colleagues reflect the contemporary medical discourse. Restless, inattentive children were thought to have both attention and moral control deficits. It is only modern medical accounts of these children, that have retrospectively 'diagnosed' them with what we now term ADHD.

Nevertheless, the theory of a 'flawed brain' continues (Bentall [15], 2004; Southall [67], 2007).The medical account of ADHD is far from being a unified discourse; debate about its etiology, diagnosis and treatment continues (Hammond [47], 2008; Visser and Jehan [74], 2009). Opponents of the medical discourse have developed alternative approaches to explaining and treating ADHD, such as the psychodynamics account (Conway [22], 2012) and the social construct account (Conrad and Bergey [21], 2014; Timimi and Taylor [73], 2004). Both see the origin of the problem in factors external to the child.

\subsection{ADHD: Media Constructions}

Due to the lack of literature investigating Twitter representations of ADHD, I draw upon articles describing portrayals of ADHD in Western media more broadly. Media portrayals influence the ways in which people 
understand and perceive disability (Englandkennedy [27], 2008). Media framing is "a process through which a communication source defines and constructs a public issue or controversy, and can have significant consequences for how people view and understand an issue" (Schmitz et al. [65], 2003, p.386). Media framing contributes to the normalizing or stigmatizing of mental disorders, so analyzing the ways in which individuals with mental illnesses are portrayed is crucial (Ray and Hinnant [62], 2009). The literature investigating media influence on understandings of mental health and disabilities in general is vast (Clarke [19], 2011). However, only a few studies have examined media representations of ADHD.

Lloyd and Norris [51] (1999) undertook the first analysis of UK newspaper coverage of ADHD, examining the role of media framing in the rise of the disorder. They looked at 98 reports published between 1994 and 1999 in the broadsheet and tabloid press. The authors distinguished two main discourses: "the voice of parents" and "the role of experts" (p. 506). Parents interviewed were often representatives of parents' organizations that promoted medical solutions for behavioural difficulties. Professionals were portrayed as "experts" who built their careers on treating ADHD. Lloyd and Norris[51] (1999) noted the exclusion of teachers' voices from media discourses.

Schmitz et al. [65] (2003) used social representations theory (SRT) to investigate coverage of ADHD by US newspapers from 1988 to 1997 . They found that biological perspective to be the dominant representation of ADHD, also noting that $\mathrm{ADHD}$ was portrayed as primarily affecting young white boys (Schmitz et al. [65], 2003). Horton-Salway [48] (2011) studied UK national newspapers from 2000 to 2009 for references to ADHD, finding two perspectives at work: the biological and the psychosocial. In her research, the latter was the dominant view, leading to moral judgments about poor parenting in a "sick society" and calls for better parenting as the solution (Horton-Salway [48], 2011). This dominant early $20^{\text {th }}$ century representation disputed the medicalization of children with $\mathrm{ADHD}$, which, until then, had not been widely questioned (Norris and Lloyd [57], 2000; Schmitz et al. [65], 2003).

Media presentations of ADHD echo scholarly debates regarding the complexity of $\mathrm{ADHD}$ and the lack of consensus on the origin and treatment of the disorder. Those who advocate the biological view find the ADHD label a justification for a child's behaviour, interpret medical intervention as helping the child manage difficult behaviour, and see the explanation of neurobiological dysfunction as key to the removal of stigma from parenting (Norris and Lloyd [57], 2000; Schmitz et al. [65], 2003). Those who advocate the psychosocial perspective, however, perceive the use of medication as a highly suspect means of social control (Norris and Lloyd [57], 2000). These controversies surrounding ADHD are far more multi-layered than the biological/psychosocial binary would indicate (Nigg [56], 2006). Accordingly, the media is merely circling and countering parental and expert discourses (Lloyd and Norris [51], 1999; Norris and Lloyd [57], 2000).

But how is ADHD portrayed in the media? The study of US newspapers by Schmitz et al. [65] (2003) found that ADHD was objectified, with negative images of a "broken brain" and "derailed concentration" used to characterize it. Englandkennedy [27] (2008) analyzed US television portrayals of ADHD and concluded:

Few media representations of ADHD exist and most are inaccurate; they reflect and reinforce social concerns and negative stereotypes. Perceptions of ADHD and people who have been diagnosed as 'having it' reflect an overarching sociocultural belief that this is an illegitimate category of disability. (p.112).

The author described common beliefs about ADHD: that it is a childhood disorder; that it is easily diagnosed; that it is caused by 'abuse' of stimulants by the child or other family members; and that the label is used to excuse bad behaviour.

The image of children with ADHD and their parents is mostly negative, with few media accounts portraying them positively (Horton-Salway [48], 2011). A child with ADHD is described as a "problem child, [or an] abnormal or ordinary naughty child" (Horton-Salway [48], 2011, p. 533 ), or as the disruptive or deviant young white male (Horton-Salway [49], 2012; Schmitz et al. [65], 2003). Parents of children with ADHD - primarily mothers - are characterized as ineffectual or neglectful (Horton-Salway [48], 2011), and consequently feel blamed. Their parenting skills were often seen as the root of the problem (Lloyd and Norris [51], 1999). Parents felt "distraught," "frustrated," "confused," as if they were "in a nightmare," "embarrassed," and victims of their child's condition (Norris and Lloyd [57], 2000).

Gendering is deeply embedded in media discourse on ADHD (Horton-Salway [48], 2011, 2013; Schmitz et al. [65], 2003). As previously mentioned, ADHD is portrayed as a predominantly young male phenomenon (Horton-Salway [48, 49], 2011, 2012; Schmitz et al. [65], 2003). Yet the ratio of boys to girls with ADHD is between $3: 1$, this may decrease with age to $1: 1$ in adults (Swanson et al.[69], 1998). Clearly many girls/women are affected.

Media articles representing fathers' perspectives are scarce, while those representing mothers are more common (Horton-Salway [49], 2012; Schmitz et al. [65], 2003). Mothers are stereotyped as the parent who speaks for the child, while fathers tend to be invisible. Horton-Salway [49] (2012) argues that the absence of fathers in media accounts does not portray the typical family experience, but reflects assumptions that if something is wrong with a child's behaviour, it is the mother fault. 


\subsection{ADHD Studies in Saudi}

In 1996, ADHD was first acknowledged in Saudi studies. Abdur-Rahim et al. [1] (1996) surveyed the services offered in a child psychiatric clinic in Riyadh. The authors examined 199 records of patients aged 14 years or younger over a six-year period. Although this study examined children's psychological problems in general, it highlighted the prevalence of ADHD within this population, which represented $12.6 \%$ of patients (Abdur-Rahim et al. [1], 1996). Most of the ADHD studies that followed were quantitative (e.g. Taleb and Farheen [71], 2013; Jenahi et al. [41], 2012). Some studies have assessed knowledge or perceptions of ADHD among parents and/or teachers (Zaki [78], 2013; Abed et al. [2], 2014; Munshi [54], 2014; Alamiri and Faulkner [4], 2010). These studies found that teachers and parents have basic knowledge of ADHD, but little understanding of causes and possible interventions.

\section{Methodology}

This article examines the representations of ADHD by AFTA Society members on Twitter within Saudi Arabia. Foucauldian discourse analysis (FDA) is applied in an analysis of how ADHD is discursively constructed through AFTA Society tweets.

Foucault's work acknowledges the uncertainty of 'truth' and the pluralism of meaning in analyzing discourse, which underscores the message that literal meaning should not be the focus for discourse analysts. This is not to suggest that 'anything goes'; on the contrary, it is an invitation, to use a Foucauldian term, to create a space to be able to rethink. What is important, then, is not what the discourse means literally, but what it conceals, and what it achieves. The point of this approach is to "[concentrate] on the relations of power and knowledge in modern society" (Dreyfus and Rabinow [25], 1982, p. 105). It involves exposing as much as possible the conditions of stability, presence, authority, and power relations when analyzing social institutions (Said [63], 1978) in lieu of accepting grand narratives (Williams [76], 2005) and the notion of absolute truth. A commitment to revealing underlying forces as described by Said justifies the use of FDA in this study. It fittingly supports the aim of this research: to identify the discourses emerging on the AFTA Society platform regarding ADHD and assess their implications for understanding and treating ADHD.

FDA is concerned with the role of language in the formation of social life. Foucault [28] (1972) describes discourse as "practices that systematically form the objects of which they speak" (p.42). Discourse, then, involves social and ideological practices which not only control how individuals think, interact, and behave (Baxter [14], 2002), but also form the reality of what they say. Parker [58] (1992) describes the notion of discourse, in a Foucauldian sense, as facilitating and limiting, enabling and constraining what can be said, by whom, where and when.

Given that FDA acknowledges the link between discourse and power, and questions the subject positions occupied within discourse and its implications for subjectivity and experience (Willig [77], 2008), it was particularly insightful for the present research. Throughout Foucault's work, he is reluctant to outline his approach clearly (Tamboukou [70], 1999). He states, "I take care not to dictate how things should be" (Foucault [32], 1994, p. 288). This reticence has generated various guidelines by subsequent discourse analysts. Willig's [77] method (2008), in six stages, answers the following questions:

- Discursive constructions: what are the ways in which the discursive object is constructed?

- Discourses: what are the various discursive constructions of the object within wider discourses?

- Action orientation: what are the functions and benefits of constructing the object in a specific way?

- Positioning: what are the different subject positions that these discourses offer?

- Practice: What is the relationship between discourse and practice?

- Subjectivity: What is the relationship between discourse and subjectivity?

\subsection{Data Collection and Analysis}

In this study, I investigated which ADHD discourse(s) the AFTA Society was (re)producing in their Twitter account and what the implications were for ADHD practices. The ADHD Society Twitter (@adhdarabia) has over 13,500 followers. Tweets posted between December $1^{\text {st }}, 2016$ to January $31^{\text {st }}, 2017$ were collected, with those announcing AFTA events and retweets from other accounts eliminated. This resulted in 141 tweets that discuss experiences of ADHD, explain the nature, causation, or treatment of ADHD, and represent experts, teachers, and parents.

\subsection{Analysis and Discussion}

In analyzing the tweets, I will be following Willig's six stages to answer his accompanying six questions. However, for reasons of space, related stages will be combined. Stages 1 and 2 will be discussed together, as will stages 4 and 5 .

\subsubsection{Stages 1 and 2: Twitter Discourses and the Discursive Construction of ADHD}

The first stage of the analysis involves identifying all the references, whether explicit or implicit, of the discursive object constructed in the text (Willig [77], 2008). The discursive object discussed in the sampled tweets concerns 
ADHD. Stage 2 locates the different constructions of the discursive object within wider discourses (Willig [77], 2008).

The first discursive construction that emerges is that of ADHD as involving suffering. Terms used to describe the effects or consequences of ADHD include "suffering", "problems", or the use of explicit references. For example:

"The ADHD child suffers from impulsivity, inattention, and hyperactivity, so teachers may face difficulty in dealing with him."

Other tweets refer to 'problems' caused by having ADHD:

"Children diagnosed with ADHD often suffer at an early age from social problems such as rejection by their peers."

"There is a high probability that ADHD children will suffer from sleeping problems."

Another example of the construction of suffering is the reference to ADHD as a "condition" and children with ADHD as "cases". The use of such language to imply the impersonal, medical nature of the problem constructs the discursive object as something unspeakable and unknowable, at least by those who are non-expert (Willig [77], 2008). For example:

"The condition requires expert diagnosis as it covers a wide range of behaviours."

"This defect is often the result of a genetic factor in up to $90 \%$ of cases."

Such statements construct the child with ADHD as a sufferer, subject to other problems, undergoing unknowable experiences. This reflects a deviance discourse, in which subjects are classified as 'abnormal'. Through concepts of deviancy, ADHD resonates with wider medical and psychological discourses. Busfield [16] (1986) notes that "It is science that permits the boundary between the 'normal' and 'pathological'; it is science that creates possibilities of accurate identification of the mentally ill; it is science that provides effective methods of cure" (p.17). These scientific discourses claim to understand the reasons behind the 'suffering', while suggesting interventions that aim to lessen the 'suffering' experience.

Presenting ADHD as constituted by suffering, medical discourse provides the primary terminology in tweets about ADHD, including scientific descriptions of symptoms, diagnoses and treatments. This terminology circulates between language users in a way that makes it almost impossible to talk meaningfully about ADHD without drawing on medical concepts. As Danforth and Navarro [23] (2001) conclude, "Medical discourse... is so dominant that language users have little choice but to contend with it in some fashion, whether they appropriate the discourse with reflexive acceptance, mild modification, or dramatic resistance" (p.173). This allows the medical discourse to become the "regime of truth" (Foucault [30], 1977) against which childhood itself is judged.

Psychological approaches have the advantage of including caregivers in the behavioural modification process (Cione et al. [18], 2011; Widener [75], 1998). Although the medical discourse provides the primary framework for discussions of the disorder, the psychological discourse, in AFTA Society tweets, seems to function as a supplement: that is, the medical process of diagnosis and use of pharmaceutical treatment is accepted alongside endorsements of the importance of behavioural interventions for children with ADHD.

An alternative discursive construction of ADHD is the notion that caring for a child with ADHD is a 'different' kind of responsibility for parents and teachers. Thus, although it is normal for parents to care for their children without interference from others, and for teachers to teach without advice from other professions, parents and teachers of ADHD children must be advised by 'experts'. This was presented in various ways, some tweets constructing parents of children with ADHD as responsible for surveillance - a very Foucauldian concept. For example, parents should:

"Note their capacity for concentrating."

"Gauge the seriousness of a problem. Children with ADHD are regularly disruptive at school and at home. Their behaviour causes problems in their relationships with both adults and other children."

Then, following diagnosis, the parents' must be role models:

"Tips to help your child continue to focus and organize: (be an example of cleanliness and organization). Prepare the house in an organized way, and make sure that the child knows where everything is."

"Tips to help your child continue to focus and organize: (Follow a routine). It is important to set a date and place for everything to help a child understand and meet expectations."

Most tweets constructed parents of children with ADHD as responsible for modifying their children's behaviour:

"To improve communication with your inattentive child, you should always make eye contact with him before talking."

"There are several things parents can do to help their children with ADHD to sleep better."

"Role-play with the child the social situations that he may face and switch the roles between you. Do it in a fun way so the child will interact with you."

The construction of parents of children with ADHD as being responsible for special care of their children with ADHD draws upon different discourses. The criteria and duration of the behaviours that parents have to "note" and "gauge" resonate with the APA's DSM discourse, describes the criteria and duration of symptoms indicating a diagnosis of ADHD. This clinical gaze, as Foucault [29] (1975) calls it, has been extended beyond medical experts to parents, who are expected to monitor and observe children for possible symptoms. It operates in a multi-directional manner to the point of parental 
surveillance over the supervisors themselves. This leads to other constructions of parents as role models, and the need to supervise their own behaviours, in line with the strategies that parents are advised to follow, which echo the psychological discourse. Failing to comply with 'expert' advice, such as that offered by the AFTA Society, lends substance to a discourse of guilt and bad parenting (Klasen and Goodman [45], 2000).

Foucault [29,31] $(1975,1988)$ emphasises that the description of disorders works to supply the human sciences with a locatable object of scrutiny. Following Foucault, then, the effect of words such as "note" and "gauge" serve to privilege the DSM discourse of the "behaviourally disordered" child. One implication of such language is the codification of practices of self-regularity in an attempt to regulate the ADHD child.

Tweets directed at teachers take two main forms. One constructs teachers as probably the first adults who will suspect ADHD in a student:

"You remember how it was when your teacher told us that it might be ADHD and we ought to see the doctorwhat a weight off our shoulders."

"... and above all don't suffer in silence, talk to a teacher or a GP and get the help you need."

The second form of tweets for teachers presents strategies that male teachers ${ }^{3}$ could use in helping male students with ADHD:

"It is possible to increase the focus of the student with ADHD in the classroom by reducing the visual and audio effects that distract his attention."

"Give an ADHD child a chance to stand and move reasonably by giving him some tasks to accomplish that allow him to move within the allowed school protocol (such as cleaning the blackboard, distribution of cards)."

The construction of students with ADHD as males by employing the pronouns 'his' and 'him' echoes the generalising discourse and constructs the discursive object as a male disorder. I argue here that the portrayal of ADHD as a male disorder is problematic because ADHD is recognized to exist in both males and females. Staller and Faraone [68] (2006) estimated that 32 million females worldwide have ADHD, which make their diagnosis an important public health concern. Given that there is no corresponding advice for female teachers of girls. The assumption is that only boys have ADHD and only men teach them. No guidance is provided for women teachers. Tweets that present ADHD as if it involves only boys have the potential to impact girls and women with ADHD negatively by overlooking them or misinterpreting their symptoms merely as behavioural problems. Gershon and Gershon (2002) suggest that referral bias continues to overlook ADHD in females, especially in younger girls.

The construction of teachers of students with ADHD as

3 In Saudi, girls are taught by female teachers separately from boys from the beginning of education. gatekeepers and the description of behaviours that teachers should notice draw upon the DSM discourse. In this discourse, teachers are part of the assessment process for ADHD. The behavioural strategies that teachers are advised to implement in the classroom resonate with the psychological discourse.

\subsubsection{Stage 3: Action Orientation}

This stage examines the outcomes and implications of constructing the discursive object in a particular way (Willig [77], 2008). By constructing ADHD as an experience of suffering, this could help authors/professionals to achieve and secure the status of experts; they are qualified to provide advice and support for 'sufferers' reinforced. The AFTA Society's use of the term 'suffer' in conjunction with the schooling discourse (i.e. "the ADHD child suffers from impulsivity, inattention, and hyperactivity, so teachers may face difficulty in dealing with him") may justify the series of lectures that the AFTA Society is conducting in separate male and female schools in Saudi "to raise awareness among teachers about ADHD" (Teacher Training [72] n.d.). In addition, the Society's use of medical discourses may support their projects such as their charity clinic or 'Your Consultant', a program that provides free medical and psychological counselling services by telephone in collaboration with specialists. It also allows them to attribute the ultimate responsibility for diagnosis and treatment to medical professionals.

The construction of caring for a child with ADHD as a 'different' kind of responsibility for parents and teachers serves to emphasize the medical discourse, positioning a child as 'suffering' from "a neurological disorder caused by a defect in the structure of the brain" (Southall [67], 2007). The AFTA Society definition of ADHD subscribes to interpretations that situate mental disorders and treatment approaches firmly within the realm of medicine. This undermines parents' ability to care for their children with ADHD without 'expert' advice. AFTA Society tweets addressed to parents and teachers imply that neither parental styles nor teacher training entail the expertise to implement treatment strategies without professional advice. Illustrating Foucault's ideas, medical knowledge is fundamental to the exercise of 'expert' power, creating a hierarchy of knowledge and credibility, and a distance between professionals and caregivers.

\subsubsection{Stages 4 and 5: Positioning and Practice}

Stage 4 examines the subject positions offered by constructions of the discursive objects (Willig [77], 2008). Stage 5 outlines the possibilities for action contained within discursive constructions.

Constructions of ADHD as 'suffering' portray those with $\mathrm{ADHD}$ as having poor quality of life. They 'suffer' both from ADHD symptoms and from the impact of having these symptoms: i.e. they are subject to other social, 
emotional, physical and financial problems. This opens up the opportunity for medical processes, including medications, which could give children with ADHD the means to control their symptoms. This, in turn, may lessen their 'suffering,' with additional psychological interventions moving the child toward the ultimate goal: normalization of their behaviour. This construction positions people with ADHD as highly dependent on others, through their need for medical, psychological and educational interventions.

By constructing caring for children with $\mathrm{ADHD}$ as a 'different' kind of responsibility for teachers, children with ADHD are positioned as 'difficult' to handle. The notion that all children with ADHD are difficult to deal with creates preconceptions; Saudi teachers' knowledge of ADHD comes mainly from reading about it (Munshi [54], 2014). Such tweets from an apparently expert body generalize the characteristics of students with ADHD and close down the opportunity for these students to prove that they might not be difficult to handle. The negative portrayal of the condition may lead to limits on the number of students with ADHD permitted in each classroom and could even result in their exclusion.

Tweets containing strategies for teachers to use to alleviate symptoms of students with ADHD imply that teacher training, self-efficacy and past experience is insufficient preparation for teaching such students. Yet Sciutto et al. [64] (2000) examined 149 elementary New York school teachers' knowledge of ADHD using the Knowledge of Attention Deficit Disorders Scale (KADDS) and found that teacher self-efficacy, prior exposure to an ADHD child, and past teaching experience were all positively related to ADHD knowledge.

The construction of raising a child with ADHD as a 'different' kind of responsibility for parents, positions parenting style as similarly insufficient because their children are considered disordered. Thus, parents need advice from ADHD 'experts' (“... .always make eye contact with him before talking"). While tweets like these may intend to be helpful, they may also constrain parenting freedom and can position parenting styles as a threat to the way things 'should' be. Parents of children with ADHD must re-formulate their parenting experience to follow the expert advice that will produce "children who are orderly and productive and as such maintain and continue the ways of society" (Austin and Carpenter [10], 2008, p.379).

\subsubsection{Stages 6: Subjectivity}

The last stage in the analysis explores the relationship between discourse and subjectivity. As Willig [77] (2008) puts it, "Discourses make available certain ways of seeing the world and certain ways of being in the world," (p. 154), giving meaning to our social and psychological realities. This final stage is concerned with the effect of the subject positions on the subject's thoughts, feelings, and experiences.
Some of the discourses identified on Twitter have the power to create a problematizing subjectivity for children with ADHD. This construction of the subject position of the problem child reveals how a child's identity is constructed through descriptions of disorderly behaviour. As a result, children with ADHD are classified as deviants in need of expert intervention. This classification creates a false dichotomy: children are either 'normal' or 'abnormal', and those who 'suffer' from ADHD are the latter. Foucault acknowledges that Western culture often depends on binary oppositions, which are always hierarchic, valuing one term over the other. He attacks the notion of binary opposites for their hidden privileges, arguing that the preferred term is not exempt from the negative qualities attributed to the other term, and that these terms are not symmetrically opposite or mutually exclusive (Foucault [29], 1975). But it is not only Western culture that uses binary opposites. As knowledge about ADHD is translated and circulated into other cultures, such approaches are reinforced and extended. AFTA Society constructions of ADHD merely circulate existing, dominant, sometimes misleading Western discourses, but does not critique or challenge them.

Ultimately, using terms like 'ADHD child' not only limits the human being to his/her disorder, but also limits the historically situated meanings people give to the behaviours that constitute the disorder (Hacking [37], 1999).

Applying concepts of deviance, medical practices are deemed correct. Children with ADHD become subject to such practices by those who understand the 'problem' with the aim of lessening the 'suffering':

Due to their dependency upon the adult world for everything from basic sustenance to education and recreation, children are especially subject to the social ramifications of the ADHD diagnosis. Through the eyes of their educators, clinicians, and parents, the ADHD child's world requires regulation to promote the "management" of his/her disorder. Invariably, the active agents in this management are the authority figures surrounding ADHD children. In applying the ADHD mental disorder label to a child, adults take on the responsibility for structuring the child's life to meet the perceived treatment requirements in conjunction with the diagnosis (Rafalovich [60] 2001, p. 373).

This analysis has also revealed that caring for a child with ADHD is considered a 'different' kind of responsibility. This discourse has the power to change the way in which parents or teachers think about children with ADHD. For parents, the portrayal of children with ADHD as 'difficult' to care for may influence them to conceal a diagnosis of ADHD from the school or from other people. This would be an attempt to protect their children from being seen as problematic; parents will also know that they 
are often considered part of the 'problem' (Johnston [42], 1996; Klasen and Goodman [45], 2000; Neophytou [55], 2004).

Teachers may have negative feelings about having students with ADHD in their classrooms and may oppose their inclusion. I examined teachers' perspectives on including students with ADHD in regular classrooms (Alharbi [5], 2017). Six teachers (five general and one special education) from three districts in Jeddah reported resistance to full inclusion. They felt that each decision must be made on a case-by-case basis, and assumed that such students require a range of support services.

\section{Conclusions}

Critically examining the relationship between Twitter framing and ADHD can give researchers a more comprehensive understanding of the construction of ADHD in the Saudi Arabian society, particularly when studied in conjunction with the broader scholarly literature on the subject. Collectively, these findings could encourage Saudi Arabian society to move beyond the dominant discourse stigmatizing children with ADHD as "disorderly kids" who "need to be fixed." By considering Twitter framings in the broader context of ADHD literature, we can identify negative portrayals of ADHD by social media producers and begin to develop discourses and practices that take advantage of the power of social media to create positive change.

\section{REFERENCES}

[1] Abdur-Rahim, F., Al-Hamed, A., Chaleby, K. and Al-Subaie, A. (1996). A survey of child psychiatry clinic in a teaching hospital in Saudi Arabia. Saudi Medical Journal, 17(1), 36-41.

[2] Abed, M., Pearson, S., Clarke, P., and Chambers, M. (2014). Saudi Arabian Teachers' Knowledge and Beliefs about ADHD. Journal of the International Association of Special Education, 15(1), 67-74.

[3] ADHD Society and Support Group. (2008). AFTA information. Riyadh, Saudi Arabia: AFTA.

[4] Alamiri, F., and Faulkner, M. (2010). Challenging Gifted Children and the Phenomenon of AD/HD: A Qualitative Study of Teachers' and Parents' Perceptions in a Saudi Arabian Primary School. Australasian Journal of Gifted Education, 19(1), 6-15.

[5] Alharbi, R. S. (2017). Attention-Deficit Hyperactivity Disorder (ADHD) Discourses in Saudi Arabia (Unpublished doctoral dissertation). University of Ottawa, Canada.

[6] Almahmoud, J. (2015). Framing on Twitter: How Saudi Arabians intertextually frame the Women2Drive campaign. Georgetown University. Retrieved from https://search-proquest-com.proxy.bib.uottawa.ca/docview/ 1679935996? accountid=14701

[7] Alothman, A. B. (2013). A survey of social media users in Saudi Arabia to explore the roles, motivations and expectations toward using social media for social and political purposes (Order No. 1541900). Available from Dissertations and Theses @ Arkansas State University; ProQuest Dissertations and Theses Global. (1419422776). Retrieved from

https://ezproxy.library.astate.edu/login?url=http://search.pr oquest.com/docview/1419422776? accountid $=8363$ (accessed 17.07.17).

[8] Anthony, S. M., and Zhang, W. (2017). Alternative Tweeting: A Comparison of Frames in Twitter's Political Discourse and Mainstream Newspaper Coverage of the Singapore General Election of 2011. In M. Adria, and Y. Mao (Eds.), Handbook of Research on Citizen Engagement and Public Participation in the Era of New Media (pp. 324-343). Hershey, PA: IGI Global. doi:10.4018/978-1-5225-1081-9.ch018

[9] American Psychiatric Association. (2013). Diagnostic and statistical manual of mental disorders (DSM-5®). American Psychiatric Pub.

[10] Austin, H., and Carpenter, L. (2008). Troubled, troublesome, troubling mothers: The dilemma of difference in women's personal motherhood narratives. Narrative Inquiry, 18(2), 378-392.

[11] Barkley, R. A. (1990) Attention Deficit Hyperactivity Disorder: A Handbook for Diagnosis and Treatment, fourth ed. Guilford Press, New York.

[12] Barkley, R. A. (2006). The relevance of the Still lectures to attention-deficit/hyperactivity disorder: a commentary. Journal of Attention Disorders, 10(2), 137-140.

[13] Barkley, R. A., and Peters, H. (2012). The earliest reference to ADHD in the medical literature? Melchior Adam Weikard's description in 1775 of "attention deficit" (mangel der aufmerksamkeit, attentio volubilis). Journal of attention disorders, 16(8), 623-630.

[14] Baxter, J. (2002). Competing discourses in the classroom: A post-structuralist discourse analysis of girls' and boys' speech in public contexts. Discourse and Society, 13(6), $827-842$.

[15] Bentall, R. P. (2004). Madness explained: Psychosis and human nature. Penguin UK.

[16] Busfield, J. (1986). Managing Madness Changing Ideas and Practice. Hutchinson, London

[17] Block, G. H. (1977). Hyperactivity: A cultural perspective. Journal of Learning Disabilities, 10(4), 236-40.

[18] Cione, G. F., Coleburn, L. A., Fertuck, E. A., and Fraenkel, P. (2011). Psychodynamic play therapy with a six-year-old African American boy diagnosed with ADHD. Journal of Infant, Child and Adolescent Psychotherapy, 10, 130-143. doi:10.1080/15289168.2011.576593.

[19] Clarke, J. N. (2011). Magazine portrayal of attention deficit/hyperactivity disorder (ADD/ADHD): A post-modern epidemic in a post-trust society. Health, risk and society, 13(7-8), 621-636. 
[20] Cha, M., Haddadi, H., Benevenuto, F., and Gummadi, P. K. (2010). Measuring user influence in Twitter: The million follower fallacy. Icwsm, 10(10-17), 30 .

[21] Conrad, P., and Bergey, M., R. (2014). The impending globalization of ADHD: Notes on the expansion and growth of a medicalized disorder. Social Science and Medicine, 122 $31-43$.

[22] Conway, F. (2012). Psychodynamic psychotherapy of ADHD: A review of the literature. Psychotherapy, 49(3), 404.

[23] Danforth, S., and Navarro, V. (2001). Hyper talk: Sampling the social construction of ADHD in everyday language. Anthropology and education quarterly, 32(2), 167-190.

[24] De Longueville, B., Smith, R. S., and Luraschi, G. (2009). Omg, from here, I can see the flames! a use case of mining location-based social networks to acquire spatio-temporal data on forest fires. In Proceedings of the 2009 international workshop on location-based social networks (pp. 73-80). ACM.

[25] Dreyfus, H. L. and Rabinow, P. (1982). Michel Foucault: Beyond structuralism and hermeneutics. Wheatsheaf, London: Harvester.

[26] Easton, N. (2013). How Twitter is driving change in Saudi Arabia. Fortune, 168(9), 76.

[27] Englandkennedy, E. (2008). Media representations of attention deficit disorder: Portrayals of cultural skepticism in popular media. The Journal of Popular Culture, 41(1), 91-117.

[28] Foucault, M. (1972). The Archaeology of Knowledge: Translated from the French by AM Sheridan Smith. Pantheon Books.

[29] Foucault, M. (1975). 2003. Abnormal: Lectures at the Collège De France, 1974-1975.

[30] Foucault, M. (1977). Discipline and punish: The birth of the prison (A. Sheridan, Trans.). London: Penguin Books.

[31] Foucault, M. (1988). Technologies of the self. In L.H. Martin, H. Gutman and P.H. Hutton (Eds.), Technologies of the self: A seminar with Michel Foucault. Amherst: University of Massachusetts Press.

[32] Foucault, M. (1994). The art of telling the truth. Critique and power: Recasting the Foucault/Habermas debate, 139-148.

[33] Gershon, J., and Gershon, J. (2002). A meta-analytic review of gender differences in ADHD. Journal of attention disorders, 5(3), 143-154.

[34] Global Digital Statistics. (2015). In We are social. Retrieved $\begin{array}{llll}\text { February } & 3, & 2015, & \text { from }\end{array}$ $\mathrm{http}: / / w w w . s l i d e s h a r e . n e t / w e a r e s o c i a l s g /$ social-digital-mobi le-in-themiddle-east-north-africa-turkey?related $=4$

[35] Goldstein, S., and Ellison, A. T. (Eds.). (2002). Clinician's guide to adult ADHD: Assessment and intervention. Academic Press.

[36] Guta, H., and Karolak, M. (2015). Veiling and blogging: social media as sites of identity negotiation and expression among Saudi women. Journal of International Women's Studies, 16(2), 115
[37] Hacking, I. (1999). The social construction of what? Cambridge, MA: Harvard University Press.

[38] Hinshaw, S., Scheffler, R., Fulton, B., Aase, H., Banaschewski, T., Cheng, W., and Sergeant, J. A. (2011). International variation in treatment procedures for ADHD: social context and recent trends. Psychiatric Services, 62(5), 459-464

[39] Hughes, A. L., and Palen, L. (2009). Twitter adoption and use in mass convergence and emergency events. International Journal of Emergency Management, 6(3-4), 248-260.

[40] Jansen, B. J., Zhang, M., Sobel, K., and Chowdury, A. (2009). Twitter power: Tweets as electronic word of mouth. Journal of the American Society for Information Science and Technology, 60(11), 1-20. doi:10.1002/asi.21149

[41] Jenahi, E., Khalil, M. S., and Bella, H. (2012). Prevalence of attention deficit hyperactivity symptoms in female schoolchildren in Saudi Arabia. Ann Saudi Med, 32(5), 462-468.

[42] Johnston, C. (1996) Parent characteristics and parent-child interactions in families of nonproblem children and ADHD children with higher and lower levels of oppositional-defiant behaviour, Journal of Abnormal Child Psychology, 24:1, 85-98.

[43] Kealey, C. (2012). The Future is Not Black and White: A Study of a Twitter-based Community of Practice on the Future of Newspapers. University of Ottawa (Canada).

[44] Kemp, S. (2015). Global digital and social media stats. 2015. In Social Media Today. Retrieved February 03, 2017, from http://www.socialmediatoday.com/content/global-digital-so cial-media-stats-2015

[45] Klasen H and Goodman R (2000) Parents and GPs at Cross-Purposes over Hyperactivity: A Qualitative Study of Possible Barriers to Treatment. British Journal of General Practice 50(452): 199-202.

[46] Krishnamurthy, B., Gill, P., and Arlitt, M. (2008). A few chirps about twitter. In Proceedings of the first workshop on Online social networks (pp. 19-24). ACM.

[47] Hammond, M. (2008). Twenty-two Lenses for a Single Diagnosis: An Ethnography of ADHD (Master's thesis). York University.

[48] Horton-Salway, M. (2011). Repertoires of ADHD in UK newspaper media. Health, 15(5), 533-549.

[49] Horton-Salway, M. (2012) 'Gendering Attention Deficit Hyperactivity Disorder: A Discursive Analysis of UK newspaper stories', Published online before print October 1. 2012. DOI: $10.1177 / 1359105312456326$. Journal of Health Psychology. Oct. $1^{\text {st }}, 2012.1359105312456326$.

[50] Java, A., Song, X., Finin, T., and Tseng, B. (2007). Why we twitter: understanding microblogging usage and communities. In Proceedings of the 9th WebKDD and 1st SNA-KDD 2007 workshop on Web mining and social network analysis (pp. 56-65). ACM.

[51] Lloyd, G., and Norris, C. (1999). Including ADHD? Disability \& Society, 14(4), 505-517. 
[52] Mannuzza, S., Klein, R. G., and Moulton III, J. L. (2003). Persistence of attention deficit/hyperactivity disorder into adulthood: what have we learned from the prospective follow up studies? Journal of Attention Disorders, 7(2), 93-100.

[53] McNeill, A. R., and Briggs, P. (2014). Understanding Twitter influence in the health domain: a social-psychological contribution. In Proceedings of the 23rd International Conference on World Wide Web (pp. 673-678). ACM.

[54] Munshi, A. M. A. (2014). Knowledge and misperceptions towards diagnosis and management of attention deficit hyperactive disorder (ADHD) among primary school and kindergarten female teachers in Al-Rusaifah district, Makkah City, Saudi Arabia. International Journal of Medical Science and Public Health, 3(4), 444.

[55] Neophytou, K. (2004). ADHD, a social construct. Australian Catholic University: Melbourne.

[56] Nigg, J. T. (2006). What Causes ADHD? New York Guilford Publications.

[57] Norris, C., and Lloyd, G. (2000). Parents, professionals and ADHD: what the papers say. European Journal of Special Needs Education, 15(2), 123-137.

[58] Parker, I. (1992). Discourse dynamics.

[59] Polanczyk, G., de Lima, M. S., Horta, B. L., Biederman, J., and Rohde, L. A. (2007). The worldwide prevalence of ADHD: a systematic review and metaregression analysis. American journal of psychiatry, 164(6), 942-948.

[60] Rafalovich, A. (2001). Disciplining domesticity: Framing the ADHD parent and child. The Sociological Quarterly, 42(3), 373-393.

[61] Rafalovich, A. (2004). Framing ADHD children: A critical examination of the history, discourse, and everyday experience of attention deficit/hyperactivity disorder. Lexington Books.

[62] Ray, L., and Hinnant, A. (2009). Media Representation of Mental Disorders: A Study of ADD and ADHD Coverage in Magazines from 1985 to 2008. Journal of Magazine and New Media Research, 11(1), 1-21

[63] Said, E. W. (1978). The problem of textuality: Two exemplary positions. Critical Inquiry, 4(4), 673-714. Retrieved from http://search.proquest.com/docview/1297265598?accountid $=14701$.

[64] Sciutto, M. J., Terjesen, M. D., and Frank, A. S. B. (2000) Teachers' knowledge and misperceptions of attention deficit/hyperactivity disorder. Psychology in the Schools, 37(2), 115-122.
[65] Schmitz, M., Filippone, P., and Edelman, E. (2003). Socia representations of attention deficit/hyperactivity disorder, 1988-1997. Culture and Psychology, 9(4), 383-406.

[66] Shepherd, A., Sanders, C., Doyle, M., and Shaw, J. (2015). Using social media for support and feedback by mental health service users: thematic analysis of a twitter conversation. BMC psychiatry, 15(1), 29.

[67] Southall, A. (2007). The other side of ADHD: Attention deficit hyperactivity disorder exposed and explained. Radcliffe Publishing.

[68] Staller, J., and Faraone, S. V. (2006). Attention-deficit hyperactivity disorder in girls. CNS drugs, 20(2), 107-123.

[69] Swanson, J.M. Sergeant, J.A. Taylor, E. Sonuga Barke, E.J. Jenson, P.S. and Cantwell, D.P. (1998) Attention Deficit Disorder and Hyperkinetic Disorder, Lancet, 351, pp. 429-433.

[70] Tamboukou, M. (1999). Writing Genealogies: an exploration of Foucault's strategies for doing research. Discourse: studies in the cultural politics of education, 20(2), 201-217.

[71] Taleb, H. A., and Farheen, A. (2013). A descriptive study of Attention Deficit Hyperactivity Disorder in Sabia City, Saudi Arabia. International Journal of Current Research and Review, 5(11), 36.

[72] Teachers Training. (n.d.). Retrieved from http://adhd.org.sa/ar/project/تدريب_المعلمين/2

[73] Timimi, S., and Taylor, E. (2004). ADHD is best understood as a cultural construct. The British Journal of Psychiatry, 184(1), 8-9.

[74] Visser, J., and Jehan, Z. (2009). ADHD: A scientific fact or a factual opinion? A critique of the veracity of Attention Deficit Hyperactivity Disorder. Emotional and behavioural difficulties, 14(2), 127-140.

[75] Widener, A. J. (1998). Beyond Ritalin: The importance of therapeutic work with parents and children diagnosed ADD/ADHD. J Child Psychotherapy, 24, 267-281.

[76] Williams, J. (2005). Understanding poststructuralism. New York: Routledge.

[77] Willig, C. (2008) Introducing qualitative research in Psychology. 2nd ed. Berkshire: Open University Press.

[78] Zaki, R. A. (2013). Enhancement the Awareness of Family Caregivers Caring for their Children with Attention Deficit Hyperactivity Disorder of the General Administration of Intellectual Education Centers in the city of Abha. Journal of American Science, 8, 9.

[79] Zappavigna, M. (2011). Ambient affiliation: A linguistic perspective on Twitter. New media \& Society, 13(5), 788-806. 